OPEN ACCESS

Edited by:

$\mathrm{Mi} \mathrm{Li}$,

The University of Tennessee,

Knoxville, United States

Reviewed by:

Sangram Keshari Lenka,

TERI Deakin Nanobiotechnology

Centre, India

Shaolong Sun,

South China Agricultural University,

China

*Correspondence:

Binling A

aibinling@catas.cn

Zhanwu Sheng

shengz@catas.cn

Specialty section:

This article was submitted to

Plant Biotechnology,

a section of the journal

Frontiers in Plant Science

Received: 04 November 2020 Accepted: 01 February 2021

Published: 19 February 2021

Citation:

Ai B, Zheng L, LiW, Zheng $X$, Yang Y, Xiao D, Shi J and Sheng $Z$ (2021) Biodegradable Cellulose Film Prepared From Banana Pseudo-Stem

Using an lonic Liquid for Mango

Preservation.

Front. Plant Sci. 12:625878. doi: $10.3389 / \mathrm{fp} / \mathrm{s} .2021 .625878$

\section{Biodegradable Cellulose Film Prepared From Banana Pseudo-Stem Using an Ionic Liquid for Mango Preservation}

\author{
Binling Ai ${ }^{1,2 *}$, Lili Zheng ${ }^{1}$, Wenqi $\mathrm{Li}^{2}$, Xiaoyan Zheng ${ }^{1}$, Yang Yang ${ }^{1}$, Dao Xiao ${ }^{1}$, Jian Shi ${ }^{2}$ \\ and Zhanwu Sheng ${ }^{1 *}$ \\ 1 Haikou Experimental Station, Chinese Academy of Tropical Agricultural Sciences, Haikou, China, ${ }^{2}$ Biosystems \\ and Agricultural Engineering, University of Kentucky, Lexington, KY, United States
}

The excessive use and disposal of plastic packaging materials have drawn increasing concerns from the society because of the detrimental effect on environment and ecosystems. As the most widely used fruit packing material, polyethylene (PE) film is not suitable for long-term preservation of some tropical fruits, such as mangos, due to its inferior gas permeability. Cellulose based film can be made from renewable resources and is biodegradable and environmental-friendly, which makes it a promising alternative to PE as a packaging material. In this study, cellulose film synthesized from delignified banana stem fibers via an ionic liquid 1-Allyl-3-methylimidazolium chloride ([AMIm][CI]) were evaluated as packing material for mangos preservation. The moisture vapor transmission rate and gas transmission rate of the synthesized cellulose film were $1,969.1 \mathrm{~g} /\left(\mathrm{m}^{2} \cdot 24 \mathrm{~h}\right)$ and $10,015.4 \mathrm{ml} /\left(\mathrm{m}^{2} \cdot 24 \mathrm{~h}\right)$, respectively, which are significantly higher than those of commercial PE films. The high permeability is beneficial to the release of ethylene so that contribute to extend fruit ripening period. As a result, cellulose film packaging significantly decreased the disease and color indexes of mangos, while prolonged the storage and shelf life of marketable fruits. In addition, the cellulose film was decomposed in soils in 4 weeks, indicating an excellent biodegradability as compared to the PE plastic film.

Keywords: cellulose film, ionic liquid, banana stem fiber, mango preservation, soil burial test, biodegradability

\section{INTRODUCTION}

Plastics are widely used in food packaging applications primarily for its low costs (Kirwan et al., 2011; Mandal, 2015). Macarthur Foundation estimated in 2016 that 78 million tons of plastic packaging is produced worldwide (Axelsson and van Sebille, 2017), and an estimated 69\% of which is contributed by food industry (Geueke et al., 2018). After short use (mostly single-use) as food packaging, $40 \%$ of the plastics packing materials, corresponding to 22 million tons, ends up in landfill and amasses in soil, which is a huge threat to underground water resources; while another $32 \%$, corresponding to 17 million tons, leaks out of the collecting and sorting systems, becomes trashes and litters all over cities and oceans, and finally enters into ecosystems and food chain 
that is fatal to human and animal health (Guillard et al., 2018). The growing concerns on health and environment call for immediate acts worldwide to develop a sustainable and biodegradable alternative to replace plastics as packaging materials.

Additionally, as the most commonly used food packing material, polyethylene (PE) film is actually detrimental to longterm shortage of some fruits. Mango is a kind of tropical fruit, which is climacteric and ethylene-sensitive. Mangoes are typically under-ripe at harvest and ripen quite rapidly after harvest. The ripening of mangos usually takes 6-7 days at room temperature, after which the fruit quality decreases, gradually becomes diseased and rotted afterward ( $\mathrm{Su}$ et al., 2001). Furthermore, the natural harvest season of mango is usually wet and rainy with temperatures of up to $35^{\circ} \mathrm{C}$, which accelerates the deterioration and decay of mangos. Packaging is a necessary and vital step for fruit preservation, which not only provides protection from physical damage, but also keeps fruits from diseases and chemical contamination so that retains freshness and nutritional quality for long-distance transportation and prolonged storage (Mangaraj et al., 2009; Guillard et al., 2018). Film packaging with an modified atmosphere has been widely used in fruit and vegetable storage (Wilson et al., 2019). Modified atmosphere packaging maintains a balance between fruit respiration and the air permeability of packaging films, which forms a microenvironment with high $\mathrm{CO}_{2}$ but low $\mathrm{O}_{2}$ so that inhibits the metabolism of fruits and vegetables and retains freshness for extended shelf life (Dhalsamant et al., 2017; Chen et al., 2019). However, as the primary packaging materials, gas permeability of PE films is limited. Therefore, from perspective of fruit preservation, it is also necessary looking for an alternative material with enhanced moisture and vapor transmission to replace $\mathrm{PE}$ films for some fruits.

As one of the primary components of lignocellulosic biomass, cellulose is biodegradable and readily available, which makes it a promising alternative to plastics for food packaging applications. However, owing to strong hydrogen bonds interactions, natural cellulose possesses high orientation and crystallinity, which makes it nearly insoluble in ordinary solvents so that limits its applications. Regenerated cellulose can be obtained by chemically modifying cellulose into carboxymethyl cellulose, cellulose xanthate (Weißl et al., 2018) or a cuprammonium cellulose complex (Sayyed et al., 2019). Ionic liquids are a new category of molten salts at room temperature and certain of them have good capability for dissolving cellulose. By formation of strong hydrogen bonds with hydrogen atoms of hydroxyls in cellulose, cellulose dissolves in ionic liquids (Zhang et al., 2017). The dissolved cellulose can be easily regenerated from ionic liquid solutions via addition of water, ethanol or acetone ( $Z$ hu et al., 2006). After its regeneration, the ionic liquids can be recovered simply by vacuum evaporation and reused for several times without significant deterioration in the performance (Mai et al., 2014). Ionic liquids have been extensively investigated as cellulose-dissolving solvents to synthesize cellulose-based materials, including blends (Mundsinger et al., 2015), composites (Mahmood et al., 2017), fibers (Hummel et al., 2015), hydrogels
(Xu et al., 2015), and other cellulosic materials (Isik et al., 2014; Zhang et al., 2017). Zheng et al. (2019) used ionic liquids $[\mathrm{Bmim}][\mathrm{Cl}],[\mathrm{Amim}][\mathrm{Cl}]$ and $[\mathrm{Emim}][\mathrm{Ac}]$ for dissolution of coniferous pulp and it was found that the regenerated films from $[\mathrm{Amim}][\mathrm{Cl}]$ had the highest crystallinity, transparency, and tensile strength. Xu et al. (2020) reported a [Amim] [Cl] based dissolution system for producing cellulose films from waste cardboard and the regenerated films had a smooth and uniform surface and high transmittance.

Banana stalk is a waste biomass after fruit harvesting produced in large volume due to each plant bearing fruit only once. The inedible parts, including pseudo-stems and leaves, representing about $88 \%$ of the weight of the whole plant (Reddy and Yang, 2015), are discarded as wastes. China alone will generate about 29.0 million tons per year of banana stalk residues ( $\mathrm{Li}$ et al., 2016). The banana pseudo-stem has a high cellulose fiber content (Guimarães et al., 2009). Therefore, banana stem is an important yet underutilized cellulose resource, which is available to be converted into a variety of value-added products. In this study, regenerated cellulose films synthesized from delignified banana stem fibers using ionic liquid [AMIm][Cl] were evaluated as packaging material for mangos preservation. Furthermore, the biodegradation properties of the cellulose films were evaluated using a compost soil burial test. The study demonstrates a promising environmental-friendly solution to the problematic plastic packaging.

\section{MATERIALS AND METHODS}

\section{Materials}

Banana stem fibers were obtained by scraping banana pseudostems, which was collected from a local banana plantation in Haikou, China. Figure 1 shows photographs of banana trees, banana pseudo-stems, banana stem fibers, and extracted cellulose by following the delignification procedure in "Delignification of Banana Stem Fibers" section. 1-Allyl-3methylimidazolium chloride ([AMIm] $[\mathrm{Cl}]$, purity $\geq 96 \%$ ) used to dissolve extracted banana stem cellulose was purchased from Chemer Chemical Co., Ltd. (Shandong, China). Mango fruits (Mangifera Indica L. cv. "Xiaotainong") were purchased from a local fruit market in Haikou, China. The fruits were just picked within a few hours and did not undergo any fresh-keeping treatment.

\section{Delignification of Banana Stem Fibers}

The banana stem fibers (shown in Figure 1c) were soaked in $\mathrm{H}_{2} \mathrm{SO}_{4}$ solution $(2 \mathrm{~g} / \mathrm{L})$ at $50^{\circ} \mathrm{C}$ for $2 \mathrm{~h}$ without agitation at a solid loading of $5 \%(\mathrm{w} / \mathrm{v})$ to remove pectin and free sugars. The solid residue was separated by filtration and washed thoroughly with DI water until the $\mathrm{pH}$ value of the filtrate is neutral. The washed solid residue was then soaked in $\mathrm{NaOH}$ solution $(200 \mathrm{~g} / \mathrm{L})$ at $30^{\circ} \mathrm{C}$ for $30 \mathrm{~min}$ to remove lignin (Shang et al., 2016). The delignified residue was thoroughly washed with DI water, squeezed to remove excess water and dried in an oven (Figure 1d). The cellulose, hemicellulose and lignin 


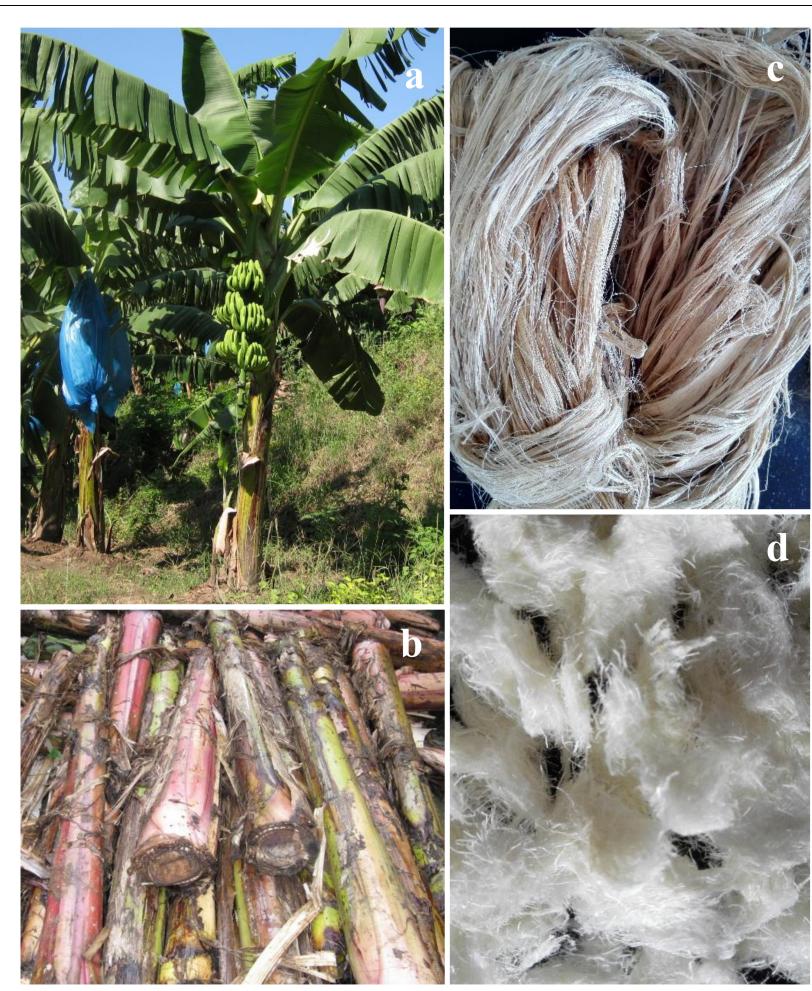

FIGURE 1 | Photographs of of (a) banana trees with fruits and leaf sheaths, (b) banana stems, (c) banana stem fibers, and (d) extracted banana stem cellulose.

contents were measured according to detergent fiber method (Soest and Wine, 1967). Briefly, by boiling in deionized water and extracting with a neutral detergent solution the soluble fraction was removed and the neutral detergent fiber residue (NDF) was obtained. Followed by the extraction with the Van Soest acid detergent, the acid detergent fiber residue (ADF) was obtained. By extracting the ADF by sulfuric acid, the acid detergent lignin residue $(\mathrm{ADL})$ was obtained. The cellulose, hemicelluloses and lignin contents are calculated as ADF-ADL, NDF-ADF, and ADL, respectively. The raw banana stem fiber contains $48.0 \%$ of cellulose, $21.1 \%$ of hemicellulose and $15.7 \%$ of lignin and the delignified residue $79.1 \%$ of cellulose, $7.6 \%$ of hemicellulose and $3.2 \%$ of lignin.

\section{Preparation of Cellulose Films}

Extracted banana stem cellulose $(1 \mathrm{~g})$ and [AMIm] $[\mathrm{Cl}](19 \mathrm{~mL})$ were loaded into a $50 \mathrm{~mL}$ round-bottom flask, and then heated in a heating mantle at $80-90^{\circ} \mathrm{C}$ with agitation at $200 \mathrm{rpm}$ for 3-4 h. Once a transparent appearance was obtained, the mixture of dissolved cellulose and ionic liquid was cast onto a glass plate and spread with a spreader to obtain a $0.5 \mathrm{~mm}$-thick layer, which was then immediately immersed in a coagulation bath (aqueous ethanol solution, 20\%) to form a cellulose hydrogel. The regenerated cellulose hydrogel was then washed at least five times with distilled water to remove residual [AMIm] [Cl]. The cellulose film was obtained by drying at room temperature.

\section{Mechanical Testing of Cellulose Films}

Mechanical testing was conducting following procedures recommended in the Chinese National Standards. According to GB/T 6672-2001 (adopted from ISO 4593-1993), cellulose film thickness was determined by using a thickness gauge (CH-10-AT, Liuling Instrument, Shanghai, China) to the nearest $0.001 \mathrm{~mm}$ at 13 positions, and the mean values was reported. Tensile properties tests were conducted using a universal testing machine (WDT20, KQL Testing Instruments, Shenzhen, China) at a crosshead speed of $1 \mathrm{~mm} / \mathrm{min}$ in accordance with the procedure specified in GB/T 1040.3-2006 (adopted from ISO 527-3:1995). Water vapor transmission were determined by sheet-cup method using a tester (W3/031, Labthink Instrument, Jinan, China) in accordance with GB/T 1037-1988 (adopted from ASTM E96-1980). The water vapor transmission (WVT) of the films was calculated by Eq. 1 .

$$
\mathbf{W V T}=\frac{24 \times \Delta \mathbf{m}}{\mathbf{A} \times \mathbf{t}}
$$

where WVT $\left(\mathrm{g} / \mathrm{m}^{2} \cdot 24 \mathrm{~h}\right)$ is the water vapor transmission rate; $\mathrm{t}$ (h) is the time required to reach an equilibrium (the increased weight of permeability cup is less than $5 \%$ ); $\Delta \mathrm{m}(\mathrm{g})$ is the weight gain during the time $\mathrm{t}$; $\mathrm{A}\left(\mathrm{m}^{2}\right)$ is the test area of the film sample.

The gas permeability was determined using an oxygen permeation analyzer (VAC-V1, Labthink Instrument, Jinan, China) in accordance with GB/T 1038-2000 (adopted from ISO 2556-1974). The gas permeability rate (GP) of the films was calculated by Eq. 2 .

$$
\mathrm{G} P=\frac{\Delta \mathbf{p}}{\Delta \mathrm{t}} \times \frac{\mathrm{V}}{\mathrm{S}} \times \frac{\mathrm{T}_{\mathbf{0}}}{\mathbf{p}_{\mathbf{0}} \mathrm{T}} \times \frac{24}{\mathrm{P}_{\mathbf{1}}-\mathbf{p}_{\mathbf{2}}}
$$

Where GP $\left(\mathrm{ml} / \mathrm{m}^{2} \cdot 24 \mathrm{~h}\right)$ is the oxygen permeability rate; $\Delta \mathrm{p} / \Delta \mathrm{t}(\mathrm{Pa} / \mathrm{h})$ is the average value of the pressure change of low-pressure chamber in unit time after oxygen permeation is stable; $\mathrm{V}\left(\mathrm{cm}^{3}\right)$ is the volume of the low-pressure chamber; $\mathrm{T}_{0}$ is standard temperature $(273.15 \mathrm{~K}) ; \mathrm{S}\left(\mathrm{m}^{2}\right)$ is the test area of the film sample; $\mathrm{p}_{0}$ is standard pressure $\left(1.01 \times 10^{5} \mathrm{~Pa}\right)$; $\mathrm{T}(\mathrm{K})$ is the test temperature; $\mathrm{p}_{1}-\mathrm{p}_{2}(\mathrm{~Pa})$ is the pressure difference between the two sides of film sample.

\section{Characterization Analysis of Cellulose Films}

The morphology of cellulosic materials was monitored using a scanning electron microscope (SEM) (S-3000N, Hitachi). Fourier-transform infrared (FTIR) spectra were obtained using an FTIR spectrophotometer (Tensor27, Bruker) by mixing ground samples with $\mathrm{KBr}$ to prepare pellets. FTIR spectra were recorded in the spectral range of $400-4,000 \mathrm{~cm}^{-1}$. Thermogravimetric analysis (TGA) was performed using a thermal analyzer (SDT Q600, TA Instruments) under a nitrogen atmosphere by increasing the heating temperature up to $800^{\circ} \mathrm{C}$ at a linear rate of $10^{\circ} \mathrm{C} / \mathrm{min}$. X-ray diffraction (XRD) analysis was performed using X-ray powder diffractometer (D8Advance, Bruker). Samples were scanned in the $2 \mathrm{q}$ range of $10-30^{\circ}$. 


\section{Preservation of Mango Using Cellulose Films}

Two sheets of cellulose film were glued together to fabricate a packaging bag (approximately $10 \times 10 \mathrm{~cm}$ in size). Plastic packaging bags of the same size were also prepared from commercially available polyethylene wrap. The mango fruits were purchased from a local fruit market without any preservation treatment. Fruits of similar shape and size, and without visible mechanical and pathological damage, were selected for preservation experiments. The selected fruits were washed with tap water for $1 \mathrm{~min}$, dried with absorbent paper, and then individually packed into cellulose or polyethylene film bags, and stored at room temperature or kept in an incubator at $11^{\circ} \mathrm{C}$. Each group consisted of at least 10 fruits. The color index, disease index, diseased fruit rate, marketable fruit rate, and weight loss ratio were calculated on days 7 and 14 .

The color index for recording the process of fruit peel degreening was calculated using equation (3) (Gong et al., 1994).

\section{Color index}

$=\sum \frac{\text { color score } \times \text { Fruit number }}{\text { The highest color score } \times \text { Total number of fruits }} \times 100$

where the following scoring system was adopted: 0 points for all green; 1 point for a yellow fruit pedicel; 2 point for localized parts turning yellow; 3 points for most parts turning yellow; 4 points for all yellow.

The disease index was evaluated by assessing the total decayed area using Eq. (4) (Gong et al., 1994).

Disease index

$$
=\sum \frac{\text { Disease score } \times \text { Fruit number }}{\text { The highest Disease score } \times \text { Total number of fruits }}
$$$$
\times 100
$$

where the following scoring system was adopted: 0 points for no visible decay; 1 point for less than $1 \%$ decay spots; 2 points for less than $20 \%$ decay spots; 3 points for more than $20 \%$, but less than $50 \%$ decay spots; 4 points for more than $50 \%$ decay spots.

Fruits with disease scores of 0 and 1 have commercial value. The total percentage of fruits with these scores was defined as the marketable fruit rate. The total percentage of fruits with scores of 1-4 is defined as the diseased fruit rate. The percentage cumulative weight loss of fruits is defined as the weight loss ratio.

\section{Biodegradability Evaluation of Cellulose Films}

The soil burial test was conducted with reference to similar methods (Rudnik and Briassoulis, 2011; Gautam and Kaur, 2013; Maran et al., 2014). This degradation test was conducted using natural microorganisms, which better reflected the degradation of biomaterials in natural environments. To facilitate the removal of samples from the soil, the polyethylene film, cellulose film, and quantitative filter paper (Xinxing 202, Hangzhou Special Paper Factory, Hangzhou, China) were clamped between two pieces of nylon mesh. A container was filled with a $10 \mathrm{~cm}$-thick soil layer, samples were tiled with nylon mesh on the soil layer, and then covered with another $10 \mathrm{~cm}$-thick soil layer. The soil moisture was maintained at approximate 50\%. Samples were taken each week, and the attached soils were carefully rinsed with deionized water. The constant weight of each sample was measured before and after degradation and the weight loss of each sample was calculated.

\section{Statistical Analysis}

Tests for statistical significance were performed using Statistical Product and Service Solutions (IBM SPSS Statistics for Windows, Version 19.0, IBM Corp., New York, United States).

\section{RESULTS AND DISCUSSION}

\section{Mechanical and Physicochemical Properties of Cellulose Films}

The intensity of ionic liquid processing significantly affects the properties of the banana stem-derived cellulose film. When the banana stem fiber-derived cellulose was treated in [AMIm] [Cl] at $90^{\circ} \mathrm{C}$ for $3 \mathrm{~h}$, the resulting cellulose film was transparent and exhibited a tensile strength of $32.8 \mathrm{MPa}$. As the intensity of treatment decrease to $80^{\circ} \mathrm{C}$ for $4 \mathrm{~h}$, the prepared cellulose film had an obviously improved tensile strength of $77.0 \mathrm{MPa}$. However, it turns to be translucent, probably due to incomplete dissolution of cellulose. The mechanical properties of cellulose films acquired through $[\mathrm{AMIm}][\mathrm{Cl}]$ treatment under different operation conditions are shown in Table 1.

The prepared cellulose films possess an enhanced permeability. The moisture vapor transmission rate and gas transmission rate are measured to be $1,969.1 \mathrm{~g} /\left(\mathrm{m}^{2} \cdot 24 \mathrm{~h}\right)$ and $10,015.4 \mathrm{ml} /\left(\mathrm{m}^{2} \cdot 24 \mathrm{~h}\right)$, respectively, which were significantly higher than those of traditional polyethylene films (Yaptenco et al., 2007; Table 1). The high permeability of cellulose film is beneficial to ethylene release in the modified atmosphere packaging of fruits and vegetables, which can delay the postharvest ripening of climacteric fruits, such as mango, resulting in an extended storage period.

The morphology changes associated with the banana stem fiber derived cellulose film can be observed from SEM images, as shown in Figure 2. Fiber bundles were separated from the banana pseudo-stem by mechanical scraping (Figure 2a) to obtain banana pseudo-stem fiber (Figure 2b). The images show that no obvious change was observed in the fiber morphology during mechanical scraping, but the fiber bundles became loose and irregular (Figure 2c) after removing lignin fraction. Cellulose film (Figure 2d) prepared from alkaline-delignified cellulose fiber by ionic liquid dissolution (at $90^{\circ} \mathrm{C}$ for $3 \mathrm{~h}$ ) had a smooth surface without obvious fibrous structure. While in the translucent cellulose film, as can be seen from Figure $2 \mathbf{e}$, the cellulose fibers were not completely dissolved, and the tiny fibers were intertwined in a network structure. As mentioned above, the mechanical strength of the translucent cellulose films was higher than that of the transparent cellulose films, probably due to the incomplete dissolution of cellulose fibers that resulted in a 
TABLE 1 | Mechanical properties of cellulose films.

\begin{tabular}{|c|c|c|c|}
\hline Test items & $\begin{array}{l}\text { Transparent cellulose film } \\
\qquad\left(90^{\circ} \mathrm{C}, 3 \mathrm{~h}\right)\end{array}$ & $\begin{array}{l}\text { Translucent cellulose film } \\
\qquad\left(80^{\circ} \mathrm{C}, 4 \mathrm{~h}\right)\end{array}$ & $\begin{array}{c}\text { Polyethylene film (Yaptenco } \\
\text { et al., 2007) }\end{array}$ \\
\hline Thickness, $\mu \mathrm{m}$ & $21.1 \pm 2.4 \mathrm{~A}^{\#}$ & $23.1 \pm 0.5 \mathrm{~A}$ & $25.1 \pm 0.6$ \\
\hline Tensile strength, MPa & $32.8 \pm 7.2 \mathrm{~A}$ & $77.0 \pm 2.5 \mathrm{~B}$ & N/A \\
\hline Extension at break, \% & $4.0 \pm 0.5 \mathrm{~A}$ & $3.1 \pm 0.4 \mathrm{~A}$ & $\mathrm{~N} / \mathrm{A}$ \\
\hline $\begin{array}{l}\text { Water vapor transmission rate, } \\
g /\left(\mathrm{m}^{2} \cdot 24 \mathrm{~h}\right)\end{array}$ & $1,969.1 \pm 88.5 \mathrm{~A}$ & $1,765.9 \pm 23.4 \mathrm{~A}$ & $\mathrm{~N} / \mathrm{A}$ \\
\hline Gas permeability rate, $\mathrm{g} /\left(\mathrm{m}^{2} \cdot 24 \mathrm{~h}\right)$ & $10,015.4 \pm 1,117.1 \mathrm{~A}$ & $9,325.8 \pm 526.9 A$ & 5,703.9-8,526.1 \\
\hline
\end{tabular}

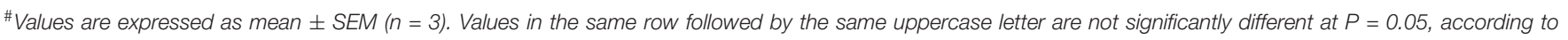
Duncan's multiple range test.

homogeneous mixture of microfibers and nanofibers. In a microand nano-hybrid cellulose film, nanofibers fill the voids among neighboring microfibers, making the hybrid film densely packed, and hence a higher mechanical strength (Wang et al., 2020).

The XRD profiles of banana stem, stem fiber and extracted cellulose show well-defined diffraction peaks at $16.4^{\circ}$ and $22.6^{\circ}$, while, clearly, that of transparent cellulose film exhibits only a broad peak at $20.3^{\circ}$ (Figure 3 ). This broad peak is considered an overlapped peak of two peaks at $20.1^{\circ}$ and $21.9^{\circ}$ and the peak of amorphous cellulose at $17.3^{\circ}$ (Xia et al., 2016), indicating that after ionic liquid dissolution and regeneration, type I cellulose was transformed into type II cellulose along with a

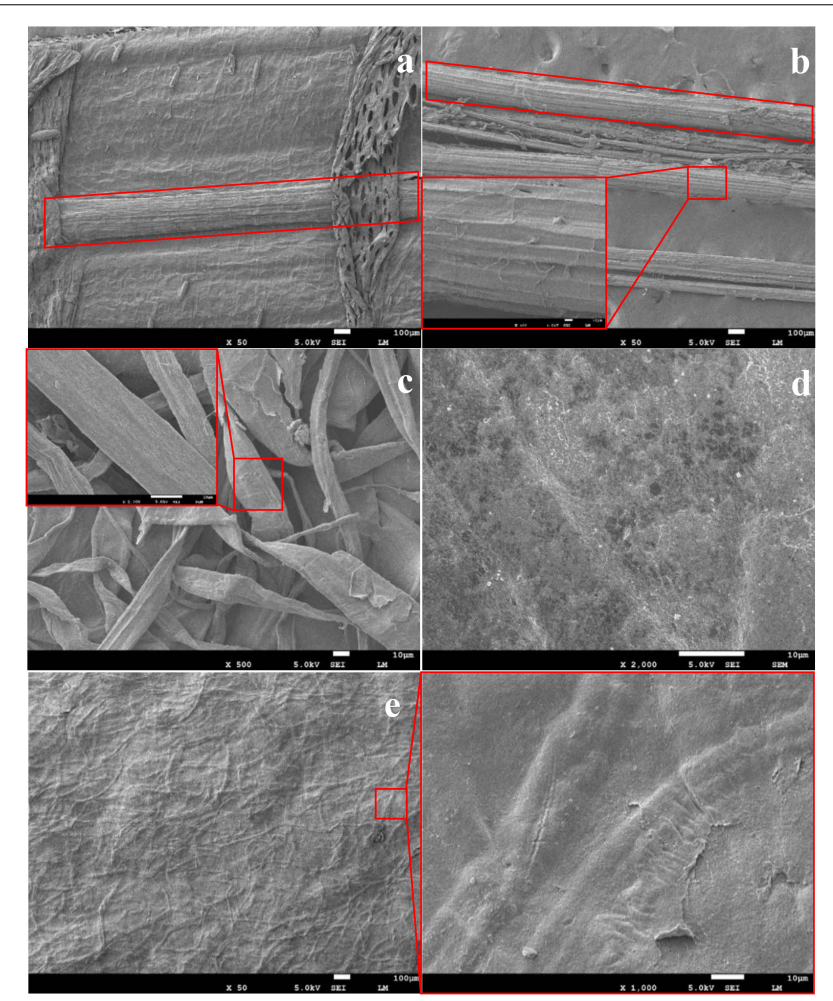

FIGURE 2 | SEM images of (a) untreated banana stem, (b) banana stem fiber, (c) extracted banana stem cellulose, (d) transparent cellulose film $\left(90^{\circ} \mathrm{C}, 3 \mathrm{~h}\right)$, and (e) translucent cellulose film $\left(80^{\circ} \mathrm{C}, 4 \mathrm{~h}\right)$. large number of amorphous cellulose structures (Cheng et al., 2012). The XRD profile of translucent cellulose film is quite different from that of transparent film. The translucent cellulose film maintained the crystal structure of type I cellulose, but the diffraction peak at $22.6^{\circ}$ had a relatively low value, indicating that part of type I cellulose transformed to type II cellulose and amorphous cellulose. This XRD result is in conformity with the SEM observation that only part of cellulose fibers was dissolved by ionic liquid when preparing translucent cellulose films. Transparency is a necessary characteristic of cellulose film, so, unless otherwise specified, the cellulose film mentioned below refers to a transparent cellulose film.

\section{Application of Cellulose Films in Mango Fresh-Keeping}

Freshness is one of the most important qualities of fruits. Fresh-keeping packaging requires good moisture-resistance, mechanical strength, and heat and mass transfer properties, which are necessary to keep the fruits hydrated and intact, and transfer heat and gas produced by the physiological activities of fruits (Soltani et al., 2015; Zhang et al., 2016). The cellulose film

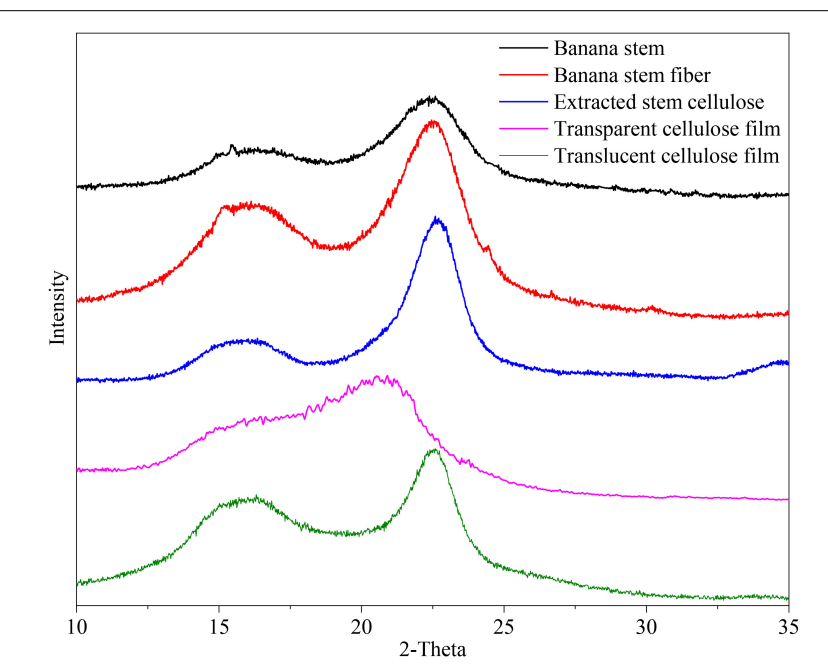

FIGURE 3 |X-ray diffraction profiles of banana stem, banana stem fiber, extracted banana stem cellulose, transparent cellulose film $\left(90^{\circ} \mathrm{C}, 3 \mathrm{~h}\right)$, and translucent cellulose film $\left(80^{\circ} \mathrm{C}, 4 \mathrm{~h}\right)$. 
has high moisture vapor transmission rate and gas transmission rate, which is good for humidity diffusion, heat dissipation and ethylene release. A high humidity results in water condensation on the surface of both film and fruits, and the in-pack condensation leads to a rapid decay (Aharoni et al., 2007). The internal heat generation from respiration and accumulation of ethylene produced by autocatalytic ethylene synthesis accelerate the ripening and even decay of fruits (Blanke, 2014). Therefore, cellulose film with high permeability could be suitable for mango preservation and storage.

Figure 4 and Supplementary Table S1 demonstrates the effectiveness of cellulose film on mongo fresh-keeping compared to $\mathrm{PE}$ film. As shown in Figure 4, polyethylene film packaging accelerated the deterioration and decay of mangoes. At room temperature, the disease indexes of mango packaged with polyethylene film was 8.5 at 7 days, which was higher than that without packaging $(5.25)$. At $11^{\circ} \mathrm{C}$, the disease indexes of mango packaged with polyethylene film was 3.5 at 14 days, which was higher than that without packaging (2.75). When cellulose film packaging was used, the disease index was significantly reduced, and the marketable fruit rate significantly increased. When stored at room temperature for 7 days, the marketable fruit rate of cellulose film packaging was $80 \%$, while those of polyethylene film-packaged and unpackaged samples were 0 and $10 \%$, respectively. Cellulose film packaging also slowed the pericarp yellowing rate. When stored at room temperature for 7 days, the color index of cellulose film-packaged pericarp was 0.5 , while those of polyethylene film-packaged and unpackaged pericarp were higher, at 8.5 and 5.25, respectively. Polyethylene is the most dominant packaging material used in fruit preservation, but not in mango preservation. Owing to the low tolerance of mango to $\mathrm{CO}_{2}$, sealed preservation using polyethylene film can accelerate mango fruit deterioration. For example, when the $\mathrm{CO}_{2}$ concentration was higher than $8 \%$ and the $\mathrm{O}_{2}$ concentration was less than $2 \%$, the color of mango pericarp turned gray and the flavor was lost (Zong, 2007).

An appropriate low temperature can effectively inhibit the respiration intensity and delay the occurrence of fruit ripening and disease (Coates and Johnson, 1997). Mango as a climacteric fruit has a very short shelf life. The shelf life ranges from 4 to 8 days at room temperature, while it can be extended to 2-3 weeks in cold storage at $13^{\circ} \mathrm{C}$ (Carrillo-Lopez et al., 2000). As can be seen from Figure 4, low temperature storage can significantly inhibit the occurrence of diseases and pericarp yellowing, increase the marketable fruit rate, and extend the storage life. When stored at $11^{\circ} \mathrm{C}$, the effect of packaging materials on mango preservation was consistent with that of storage at room temperature, with cellulose film packaging able to further improve the fruit commodity rate and extend the storage period. However, lower temperatures cannot further

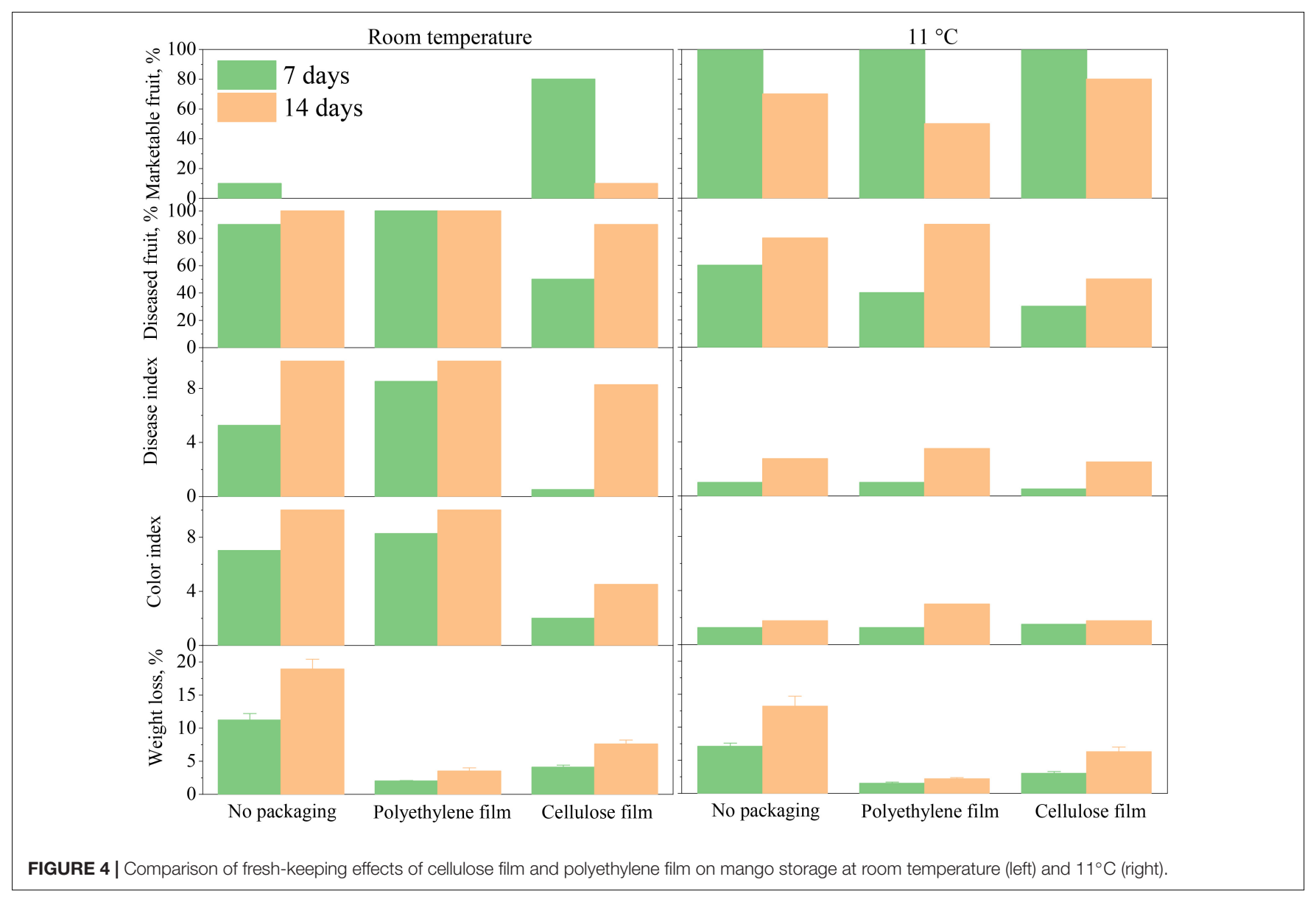


extend the storage life, on the contrary, it will cause chilling injury (Phakawatmongkol et al., 2004). The chilling injury symptoms include skin browning and pulp discoloration. The minimum tolerance temperatures of mango varied among cultivars, ranging from 10 to $13^{\circ} \mathrm{C}$ (Phakawatmongkol et al., 2004; Yan et al., 2014).

According to Liu et al., in China the annual loss of fresh fruits and vegetables in transportation is $10-20 \%$, that is, every year nearly 14 million tons of fruits and 100 million tons of vegetables are wasted in transit from farm to market (Liu, 2014). The loss rate of fruits and vegetables in developed countries is controlled within 5\% (Hailu and Derbew, 2015), because of the wellestablished cold chain facilities and infrastructure. The overall coverage rate of cold chain logistics of fruits and vegetables in Europe and US has reached more than 95\%, while that in China in 2015 is merely 19\% (Hu et al., 2019). Cold chain management is a key player in the maintenance of the quality and minimization of the loss of fresh fruits and vegetables (Mercier et al., 2017). As the results shown in Figure 4, low-temperature storage effectively maintained mango quality and significantly reduced the loss, which has a greater impact than packaging materials. However, at room temperature storage conditions, where cold storage infrastructure is scare, cellulose film packaging can help to improve the fruit commodity rate and extend the storage period.

\section{Biodegradability of Cellulose Films}

Disposable plastics are widely used in fruit packaging, but it might take hundreds of years to be decomposed in landfills. Andrady (1998) calculated that only $0.1 \%$ per year of the carbon of $\mathrm{PE}$ polymer is converted into $\mathrm{CO}_{2}$ by biodegradation under best laboratory exposure condition. In natural environment the degradation processes are even slower, as the conditions are not optimized for polymer degradation (Gewert et al., 2015).

As a biomass-based material, the cellulose film exhibited an excellent degradation property (Figure 5 and Supplementary Table S2). The mass loss of cellulose film and filter paper in the early stage of degradation was low, while the mass loss rate in

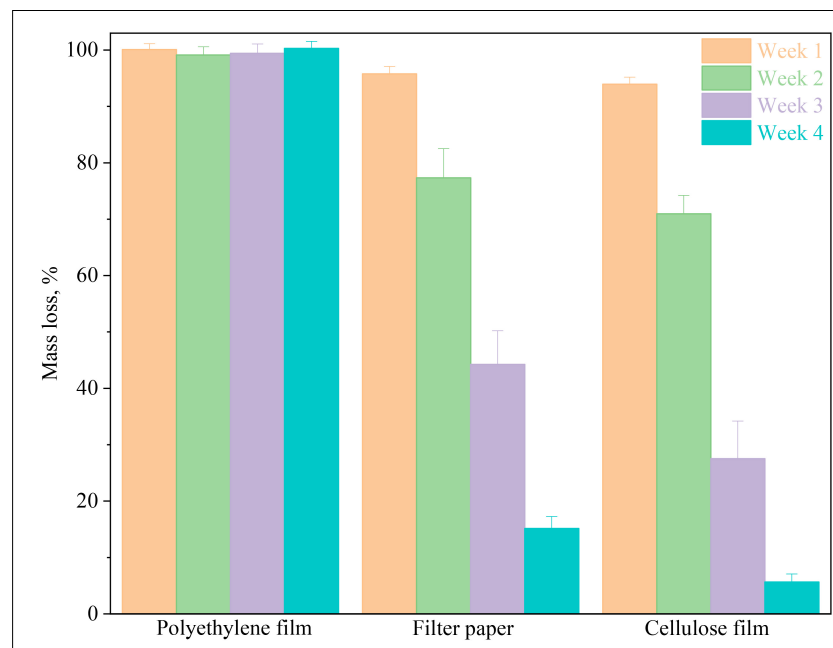

FIGURE 5 | Weight changes during 4 weeks periods in soil-buried cellulose film, polyethylene film, and filter paper. the later stage were accelerated. In the first week, about 4 and $6 \%$ by weight of filter paper and cellulose film was lost; in the following 2 weeks, filter paper lost 17 and $22 \%$ of its weight each week, respectively, and cellulose film 25 and 31\%, respectively. After 4 weeks of simulated natural degradation in soil, the mass residual rates of the cellulose film and filter paper were 7 and 15\%, respectively. Cellulose had a higher crystallinity in the filter paper, while the crystallinity of the cellulose film was decreased during ionic liquid dissolution. Moreover, the specific surface area and number of hydrophilic groups increased. These factors make the cellulose film more vulnerable to soil microorganisms (Mohan, 2011), resulting in the fast degradation of cellulose film when compared with filter paper.

As shown by the morphological characteristics of the soilburied samples (Figure 6), yellow/brown spots appeared on the surface of the filter paper and cellulose film after the first week of burying in soil, as characterized by microbial infection (Zorec et al., 2014). After the second week of burying, obvious etches, holes, and cracks appeared on the filter paper surface, while the cellulose film degraded faster and became fragmented. After the third week of burying, the holes on the filter paper surface were further expanded, while the cellulose film was completely fragmented. After the fourth week of burying in soil, the filter paper was completely fragmented, while the cellulose film showed only flocculent residues.

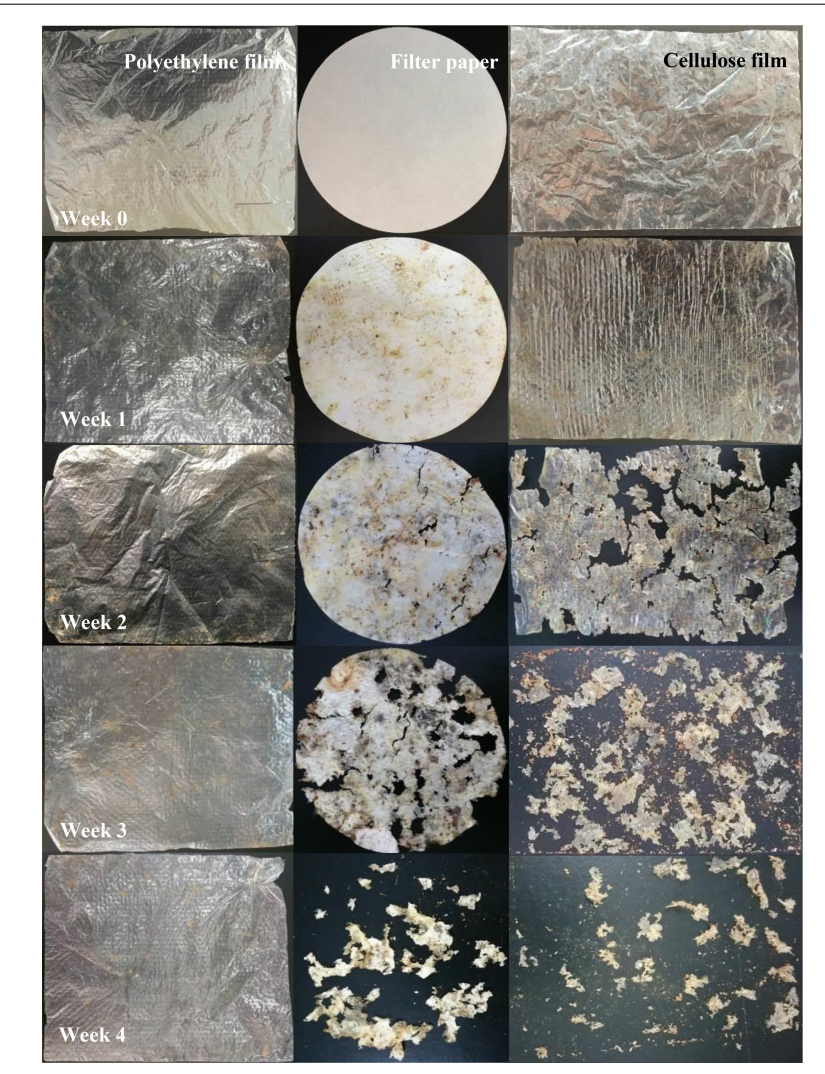

FIGURE 6 | Morphology changes of polyethylene film, filter paper, and cellulose film at different soil-burying stages. 
The soil burial method and activated sludge method for testing biodegradability of biomaterials use microorganisms existing in the natural environment to degrade tested polymers. The advantage of these methods is that they simulate in situ condition (Itävaara and Vikman, 1996). However, they have poor repeatability caused by soil and activated sludge sources, season, environmental conditions, and are not suitable for determining decomposition products. The methods using specific microorganisms and enzymes are designed to determine the inherent biodegradability of biopolymers under optimal controlled conditions. These methods may not be necessarily representative of any specific environmental conditions but they ensure repeatability (Briassoulis and Degli Innocenti, 2017). Good methods reflecting the actual process of polymer biodegradation in nature with good repeatability and reproducibility still need to be investigated.

Biodegradable films for fruits and vegetables packaging have been commercially available, derived from various biopolymers including poly(lactic acid), starch, and polyhydroxyalkanoates (Abdul Khalil et al., 2018). In present study, commercial implementation of cellulose-based film are facing many challenges. Cellulose film possesses poor mechanical properties as compared to its commercial competitors. Various additives has been proposed to use to improve the film characteristics (Abdul Khalil et al., 2018). Also, the benefits gained from the low cost of lignocellulosic feedstock is completely counteracted by the cost of ILs. Moreover, harsh solvents such as $\mathrm{H}_{2} \mathrm{SO}_{4}$ and $\mathrm{NaOH}$ were used in the processes of lignin removal and cellulose extraction, which would cause secondary pollution. Still much work is needed to be done to make the manufacturing process green. Although it is just impossible to completely replace synthetic plastics with biomaterials and it may be even unnecessary, the use of biodegradable packaging materials should be the future (Tharanathan, 2003; Siracusa et al., 2008).

\section{CONCLUSION}

Cellulose films were prepared from banana stem fibers by ionic liquid dissolution. The moisture vapor transmission rate and gas transmission rate were $1,969.1 \mathrm{~g} /\left(\mathrm{m}^{2} \cdot 24 \mathrm{~h}\right)$ and $10,015.4 \mathrm{ml} /\left(\mathrm{m}^{2} \cdot 24 \mathrm{~h}\right)$, respectively, which were significantly higher than those of commercial polyethylene films. The high permeability of cellulose film was beneficial to ethylene release, resulting in delayed fruit ripening. Cellulose film packaging decreased the disease indexes of mango, increased the marketable fruit rates, and decreased the color indexes, which could extend

\section{REFERENCES}

Abdul Khalil, H. P. S., Banerjee, A., Saurabh, C. K., Tye, Y. Y., Suriani, A. B., Mohamed, A., et al. (2018). Biodegradable films for fruits and vegetables packaging application: preparation and properties. Food Eng. Rev. 10, 139-153. doi: 10.1007/s12393-018-9180-3

Aharoni, N., Rodov, V., Fallik, E., Afek, U., Chalupowicz, D., Aharon, Z., et al. (2007). "Modified atmosphere packaging for vegetable crops using high-watervapor-permeable films," in Intelligent and Active the storage and shelf life at room temperature. The mass residual rate of cellulose film was $7.0 \%$ after 4 weeks of burying in soil, indicating that cellulose film has excellent biodegradability. This study provides a method for preparing cellulose films from lowgrade cellulosic resources as promising packaging materials for fresh-keeping tropical fruits.

\section{DATA AVAILABILITY STATEMENT}

The original contributions presented in the study are included in the article/Supplementary Material, further inquiries can be directed to the corresponding author/s.

\section{AUTHOR CONTRIBUTIONS}

BA: funding acquisition, project administration, conceptualization, resources, methodology, investigation, data curation, visualization, formal analysis, writing-original draft, and writing-review and editing. LZ: investigation, data curation, and writing-original draft. WL: writingoriginal draft and writing-review and editing. XZ, YY, and DX: investigation. JS: funding acquisition, writingoriginal draft, and writing-review and editing. ZS: funding acquisition, resources, methodology, investigation, writing-original draft, and writing-review and editing. All authors contributed to the article and approved the submitted version.

\section{FUNDING}

This work was financially supported by the Central Publicinterest Scientific Institution Basal Research Fund for Chinese Academy of Tropical Agricultural Sciences (No. 17CXTD05) and China Scholarship Council (No. 201803260012). Coauthors at University of Kentucky acknowledge support from the National Institute of Food and Agriculture, U.S. Department of Agriculture, Hatch-Multistate project under accession number 1018315.

\section{SUPPLEMENTARY MATERIAL}

The Supplementary Material for this article can be found online at: https://www.frontiersin.org/articles/10.3389/fpls.2021. 625878/full\#supplementary-material

Packaging for Fruits and Vegetables, ed. C. L. Wilson (New York: CRC Press Taylor\&Francis Group), 73-112. doi: 10.1201/9781420008 678.ch5

Andrady, A. L. (1998). "Biodegradation of plastics: monitoring what happens," in Plastics Additives, ed. G. Pritchard (Dordrecht: Springer), 32-40. doi: 10.1007/ 978-94-011-5862-6_5

Axelsson, C., and van Sebille, E. (2017). Prevention through policy: urban macroplastic leakages to the marine environment during extreme rainfall events. Mar. Pollut. Bull. 124, 211-227. doi: 10.1016/j.marpolbul.2017.07.024 
Blanke, M. M. (2014). Reducing ethylene levels along the food supply chain: a key to reducing food waste? J. Sci. Food Agric. 94, 2357-2361. doi: 10.1002/jsfa.6660 Briassoulis, D., and Degli Innocenti, F. (2017). "Standards for soil biodegradable plastics," in Soil Degradable Bioplastics for a Sustainable Modern Agriculture, ed. M. Malinconico (Berlin: Springer), 139-168. doi: 10.1007/978-3-662-541 30-2_6

Carrillo-Lopez, A., Ramirez-Bustamante, F., Valdez-Torres, J., Rojas-Villegas, R., and Yahia, E. (2000). Ripening and quality changes in mango fruit as affected by coating with an edible film. J. Food Qual. 23, 479-486. doi: 10.1111/j.17454557.2000.tb00573.x

Chen, J., Hu, Y., Yan, R., Hu, H., Chen, Y., and Zhang, N. (2019). Modeling the dynamic changes in $\mathrm{O} 2$ and $\mathrm{CO} 2$ concentrations in MAP-packaged fresh-cut garlic scapes. Food Packag. Shelf Life 22:100432. doi: 10.1016/j.fpsl.2019.100432

Cheng, G., Varanasi, P., Arora, R., Stavila, V., Simmons, B. A., Kent, M. S., et al. (2012). Impact of ionic liquid pretreatment conditions on cellulose crystalline structure using 1-ethyl-3-methylimidazolium acetate. J. Phys. Chem. B 116, 10049-10054. doi: 10.1021/jp304538v

Coates, L., and Johnson, G. (1997). "Postharvest diseases of fruit and vegetables," in Plant Pathogens and Plant Diseases, eds J. Brown, and H. Ogle (Burlington, MA: Rockvale Publications), 533-548.

Dhalsamant, K., Mangaraj, S., and Bal, L. M. (2017). Modified atmosphere packaging for mango and tomato: an appraisal to improve shelf life. J. Packag. Technol. Res. 1, 127-133. doi: 10.1007/s41783-017-0021-2

Gautam, N., and Kaur, I. (2013). Soil burial biodegradation studies of starch grafted polyethylene and identification of Rhizobium meliloti therefrom. J. Environ. Chem. Ecotoxicol. 5, 147-158.

Geueke, B., Groh, K., and Muncke, J. (2018). Food packaging in the circular economy: overview of chemical safety aspects for commonly used materials. J. Clean. Prod. 193, 491-505. doi: 10.1016/j.jclepro.2018.05.005

Gewert, B., Plassmann, M. M., and Macleod, M. (2015). Pathways for degradation of plastic polymers floating in the marine environment. Environ. Sci. Process. Impacts 17, 1513-1521. doi: 10.1039/c5em00207a

Gong, G., Chen, Y., and Zhou, S. (1994). Studies on room temperature storage of mango. Sci. Agric. Sin. 27, 82-88.

Guillard, V., Gaucel, S., Fornaciari, C., Angellier-Coussy, H., Buche, P., and Gontard, N. (2018). The next generation of sustainable food packaging to preserve our environment in a circular economy context. Front. Nutr. 5:121. doi: $10.3389 /$ fnut.2018.00121

Guimarães, J., Frollini, E., Da Silva, C., Wypych, F., and Satyanarayana, K. (2009). Characterization of banana, sugarcane bagasse and sponge gourd fibers of Brazil. Ind. Crops Prod. 30, 407-415. doi: 10.1016/j.indcrop.2009.07.013

Hailu, G., and Derbew, B. (2015). Extent, causes and reduction strategies of postharvest losses of fresh fruits and vegetables- a review. J. Biol. Agric. Healthc. 5, 49-64.

Hu, G., Mu, X., Xu, M., and Miller, S. A. (2019). Potentials of GHG emission reductions from cold chain systems: case studies of China and the United States. J. Clean. Prod. 239:118053. doi: 10.1016/j.jclepro.2019.118053

Hummel, M., Michud, A., Tanttu, M., Asaadi, S., Ma, Y., Hauru, L. K., et al. (2015). "Ionic liquids for the production of man-made cellulosic fibers: opportunities and challenges," in Cellulose Chemistry and Properties: Fibers, Nanocelluloses and Advanced Materials, ed. O. Rojas (Cham: Springer), 133-168. doi: 10.1007/ 12_2015_307

Isik, M., Sardon, H., and Mecerreyes, D. (2014). Ionic liquids and cellulose: dissolution, chemical modification and preparation of new cellulosic materials. Int. J. Mol. Sci. 15, 11922-11940. doi: 10.3390/ijms150711922

Itävaara, M., and Vikman, M. (1996). An overview of methods for biodegradability testing of biopolymers and packaging materials. J. Environ. Polym. Degrad. 4, 29-36. doi: $10.1007 / \mathrm{bf} 02083880$

Kirwan, M. J., Plant, S., and Strawbridge, J. W. (2011). "Plastics in food packaging," in Food and Beverage Packaging Technology, eds R. Coles, and M. Kirwan (Oxford: Wiley-Blackwell), 157-212. doi: 10.1002/9781444392180.ch7

Li, C., Liu, G., Nges, I. A., Deng, L., Nistor, M., and Liu, J. (2016). Fresh banana pseudo-stems as a tropical lignocellulosic feedstock for methane production. Energy Sustain. Soc. 6:27.

Liu, G. (2014). "Food losses and food waste in China: a first estimate," in $O E C D$ Food, Agriculture and Fisheries Papers (Paris: OECD Publishing), 1-29. doi: 10.1016/b978-0-12-815357-4.00001-8
Mahmood, H., Moniruzzaman, M., Yusup, S., and Welton, T. (2017). Ionic liquids assisted processing of renewable resources for the fabrication of biodegradable composite materials. Green Chem. 19, 2051-2075. doi: 10.1039/c7gc00318h

Mai, N. L., Ahn, K., and Koo, Y.-M. (2014). Methods for recovery of ionic liquids-a review. Process Biochem. 49, 872-881. doi: 10.1016/j.procbio.2014. 01.016

Mandal, G. (2015). "Value addition of fruits and vegetables through packaging," in Value Addition of Horticultural Crops: Recent Trends and Future Directions, eds A. Sharangi, and S. Datta (New Delhi: Springer), 191-199. doi: 10.1007/978-81322-2262-0_11

Mangaraj, S., Goswami, T. K., and Mahajan, P. V. (2009). Applications of plastic films for modified atmosphere packaging of fruits and vegetables: a review. Food Eng. Rev. 1, 133-158. doi: 10.1007/s12393-009-9007-3

Maran, J. P., Sivakumar, V., Thirugnanasambandham, K., and Sridhar, R. (2014). Degradation behavior of biocomposites based on cassava starch buried under indoor soil conditions. Carbohydr. Polym. 101, 20-28. doi: 10.1016/j.carbpol. 2013.08.080

Mercier, S., Villeneuve, S., Mondor, M., and Uysal, I. (2017). Time-temperature management along the food cold chain: a review of recent developments. Compr. Rev. Food Sci. Food Safety 16, 647-667. doi: 10.1111/1541-4337.12269

Mohan, K. (2011). Microbial deterioration and degradation of polymeric materials. J. Biochem. Technol. 2, 210-215.

Mundsinger, K., Müller, A., Beyer, R., Hermanutz, F., and Buchmeiser, M. R. (2015). Multifilament cellulose/chitin blend yarn spun from ionic liquids. Carbohydr. Polym. 131, 34-40. doi: 10.1016/j.carbpol.2015.05.065

Phakawatmongkol, W., Ketsa, S., and Van Doorn, W. G. (2004). Variation in fruit chilling injury among mango cultivars. Postharvest Biol. Technol. 32, 115-118. doi: 10.1016/j.postharvbio.2003.11.011

Reddy, N., and Yang, Y. (2015). "Fibers from banana pseudo-stems," in Innovative Biofibers from Renewable Resources (Berlin: Springer), 25-27. doi: 10.1007/9783-662-45136-6_7

Rudnik, E., and Briassoulis, D. (2011). Degradation behaviour of poly (lactic acid) films and fibres in soil under mediterranean field conditions and laboratory simulations testing. Ind. Crops Prod. 33, 648-658. doi: 10.1016/j.indcrop.2010. 12.031

Sayyed, A. J., Deshmukh, N. A., and Pinjari, D. V. (2019). A critical review of manufacturing processes used in regenerated cellulosic fibres: viscose, cellulose acetate, cuprammonium, $\mathrm{LiCl} / \mathrm{DMAc}$, ionic liquids, and NMMO based lyocell. Cellulose 26, 2913-2940. doi: 10.1007/s10570-019-02318-y

Shang, W., Sheng, Z., Shen, Y., Ai, B., Zheng, L., Yang, J., et al. (2016). Study on oil absorbency of succinic anhydride modified banana cellulose in ionic liquid. Carbohydr. Polym. 141, 135-142. doi: 10.1016/j.carbpol.2016. 01.009

Siracusa, V., Rocculi, P., Romani, S., and Rosa, M. D. (2008). Biodegradable polymers for food packaging: a review. Trends Food Sci. Technol. 19, 634-643.

Soest, P. V., and Wine, R. (1967). Use of detergents in the analysis of fibrous feeds. IV. Determination of plant cell-wall constituents. J. Assoc. Off. Anal. Chem. 50, 50-55. doi: $10.1093 /$ jaoac/50.1.50

Soltani, M., Alimardani, R., Mobli, H., and Mohtasebi, S. S. (2015). Modified atmosphere packaging: a progressive technology for shelf-life extension of fruits and vegetables. J. Appl. Packag. Res. 7, 33-59.

$\mathrm{Su}, \mathrm{X}$., Jiang, Y., Yu, X., and He, S. (2001). Review on postharvest biology and technology for storage and transport of mango fruit. J. Zhongkai Agrotechnical Coll. 14, 60-66.

Tharanathan, R. N. (2003). Biodegradable films and composite coatings: past, present and future. Trends Food Sci. Technol. 14, 71-78. doi: 10.1016/s09242244(02)00280-7

Wang, X., Pang, Z., Chen, C., Xia, Q., Zhou, Y., Jing, S., et al. (2020). All-Natural, degradable, rolled-up straws based on cellulose micro-and nano-hybrid fibers. Adv. Funct. Mater. 30:1910417. doi: 10.1002/adfm.201910417

Weißl, M., Niegelhell, K., Reishofer, D., Zankel, A., Innerlohinger, J., and Spirk, S. (2018). Homogeneous cellulose thin films by regeneration of cellulose xanthate: properties and characterization. Cellulose 25, 711-721. doi: 10.1007/s10570017-1576-3

Wilson, M. D., Stanley, R. A., Eyles, A., and Ross, T. (2019). Innovative processes and technologies for modified atmosphere packaging of fresh and fresh-cut fruits and vegetables. Crit. Rev. Food Sci. Nutr. 59, 411-422. 
Xia, G., Wan, J., Zhang, J., Zhang, X., Xu, L., Wu, J., et al. (2016). Cellulose-based films prepared directly from waste newspapers via an ionic liquid. Carbohydr. Polym. 151, 223-229. doi: 10.1016/j.carbpol.2016.05.080

Xu, H., Huang, L., Xu, M., Qi, M., Yi, T., Mo, Q., et al. (2020). Preparation and properties of cellulose-based films regenerated from waste corrugated cardboards using [Amim] Cl/CaCl2. ACS Omega 5, 23743-23754. doi: 10.1021/ acsomega.0c02713

Xu, M., Huang, Q., Wang, X., and Sun, R. (2015). Highly tough cellulose/graphene composite hydrogels prepared from ionic liquids. Ind. Crops Prod. 70, 56-63. doi: 10.1016/j.indcrop.2015.03.004

Yan, M., Huang, J., Lin, X., Zeng, H., and Li, X. (2014). Research progress on storage technology of mango. Acad. Period. Farm Prod. Process. 9, 72-76.

Yaptenco, K. F., Kim, J. G., and Lim, B. S. (2007). Gas transmission rates of commercially available polyethylene and polypropylene films for modified atmosphere packaging. Philipp. Agric. Sci. 90, 22-27.

Zhang, J., Wu, J., Yu, J., Zhang, X., He, J., and Zhang, J. (2017). Application of ionic liquids for dissolving cellulose and fabricating cellulose-based materials: state of the art and future trends. Mater. Chem. Front. 1, 1273-1290. doi: 10.1039/C6QM00348F

Zhang, M., Meng, X., Bhandari, B., and Fang, Z. (2016). Recent developments in film and gas research in modified atmosphere packaging of fresh foods. Crit. Rev. Food Sci. Nutr. 56, 2174-2182. doi: 10.1080/10408398.2013.819794

Zheng, X., Huang, F., Chen, L., Huang, L., Cao, S., and Ma, X. (2019). Preparation of transparent film via cellulose regeneration: correlations between ionic liquid and film properties. Carbohydr. Polym. 203, 214-218. doi: 10.1016/j.carbpol. 2018.09.060

Zhu, S., Wu, Y., Chen, Q., Yu, Z., Wang, C., Jin, S., et al. (2006). Dissolution of cellulose with ionic liquids and its application: a mini-review. Green Chem. 8, 325-327. doi: 10.1039/b601395c

Zong, Y. (2007). Research advance of storage technology of mango. Storage Process $42,5-8$.

Zorec, M., Vodovnik, M., and Marinšek-Logar, R. (2014). Potential of selected rumen bacteria for cellulose and hemicellulose degradation. Food Technol. Biotechnol. 52, 210-221.

Conflict of Interest: The authors declare that the research was conducted in the absence of any commercial or financial relationships that could be construed as a potential conflict of interest.

The handling editor declared a past co-authorship with the authors BA, WL, and JS.

Copyright (c) 2021 Ai, Zheng, Li, Zheng, Yang, Xiao, Shi and Sheng. This is an open-access article distributed under the terms of the Creative Commons Attribution License (CC BY). The use, distribution or reproduction in other forums is permitted, provided the original author(s) and the copyright owner(s) are credited and that the original publication in this journal is cited, in accordance with accepted academic practice. No use, distribution or reproduction is permitted which does not comply with these terms. 